\title{
A study on how CRM influences marketing planning in telecommunication industry
}

\author{
Naser Azad and Kayvan Darabi ${ }^{*}$
}

Department of Management, Islamic Azad University, South Tehran Branch, Tehran, Iran

CH R O N I C L E A B S T R A C T

Article history:

Received May 1, 2013

Received in revised format 10 July 2013

Accepted 12 July 2013

Available online

July 142013

Keywords:

CRM

Efficiency

Telecommunication industry

\begin{abstract}
Customer relationship management (CRM) plays an important role on marketing planning. In this paper, we re-examine the effect of having efficient CRM on efficiency of a telecommunication company. The proposed study considers three hypotheses. The first hypothesis examines whether implementation of CRM could improve customer's perception in terms of customer retention, satisfaction, loyalty and awareness. The second hypothesis examines whether implementation of CRM influences on market performance in terms of reduction on customer complaints, quality improvement, improving customer perception, access to services and increase in market share. Finally, the third hypothesis considers the effect of CRM on financial figures in terms of sales growth, profit growth, earnings per share and productivity. The results of our survey have confirmed the first hypothesis and rejected the third hypothesis. In other words, while CRM improves customer perception it does not influence financial figures in most cases $(\mathrm{P}<0.01)$.
\end{abstract}

\section{Introduction}

During the past few years, there have been tremendous efforts on learning the effect of customer relationship management (CRM) on the performance of various organizations. Keramati et al. (2010) considered different concepts of CRM, proposed a process-oriented framework for assessing the relationship among CRM resources, CRM process capabilities, and organizational performance. They classified CRM resources as "technological CRM resources" and "infrastructural CRM resources" based on the resource-based view (RBV) of the firm. Their empirical work stated that the measured constructs demonstrated key psychometric properties including reliability and validity. The results disclosed that CRM processes were more influenced by infrastructural CRM resources rather than technological CRM resources. In addition, the findings reported that firms with improved CRM process capabilities had better organizational performance.

*Corresponding author.

E-mail address: darabitct@yahoo.com (K. Darabi)

C 2013 Growing Science Ltd. All rights reserved. doi: $10.5267 /$ j.ms 1.2013 .07 .010 
According to Chang et al. (2010), CRM technology has attracted tremendous attention from researchers and practitioners as a facilitator of organizational performance. Even though firms have had tremendous investments in CRM technology, empirical research provided inconsistent support that CRM technology could enhance organizational performance. Given this equivocal impact and the increasing requirement for the generalization of CRM implementation research outside western context Chang et al. (2010) used data from Korean companies and investigated the process concerning how CRM technology could translate into business outcomes. The results highlighted that marketing capability mediated the association between CRM technology implementation and performance. In addition, a customer-centric organizational culture and management system could facilitate CRM technology implementation.

Wu and Li (2011) implemented structural equation modelling (SEM) to study the strength of the relationships among CRM, relationship quality (RQ), and customer lifetime value (CLV) from a consumer perspective. The study also tried to find out whether or not these relationship models showed significant differences based on various hotel type preference groups. In their survey, CRM had a positive influence on RQ, and RQ had a positive influence on CLV. In addition, consumer groups with various hotel preferences revealed a partial interference impact on the relationships among CRM, RQ, and CLV. Wu and Chen (2012) explored the effect of CRM on the relationship marketing effect (RME) and business performance (BP) for hotels and motels in Taiwan, and compared the differences between the two. Peltier et al. (2012) developed and examined an organizational learning framework of the relationship between organizational processes, customer data quality and firm performance. They reported that high quality customer data influces both customer and business performance.

\section{The proposed model}

The proposed study considers three hypotheses. The first hypothesis examines whether implementation of customer relationship management (CRM) could improve customer's perception in terms of customer retention, satisfaction, loyalty and awareness. The following summarizes the main hypothesis and sub-hypotheses,

First main hypothesis: There is positive relationship between CRM implementation and customer perception attributes.

The first hypothesis consists of the four sub-hypotheses summarized in Table 1 as follows,

Table 1

The summary of the first sub-hypotheses

\begin{tabular}{ll}
\hline Hypothesis & Description \\
\hline 1 & $\begin{cases}H_{0}: & \text { CRM implementation has no effect on absorbing new customers. } \\
H_{1}: & \text { CRM implementation has some positive effect on absorbing new customers. }\end{cases}$ \\
3 & $\begin{cases}H_{0}: & \text { CRM implementation has no effect on customer satisfaction. } \\
H_{1}: & \text { CRM implementation has some positive effect on customer satisfaction. }\end{cases}$ \\
4 & $\begin{cases}H_{0}: & \text { CRM implementation has no effect on customer loyalty. } \\
H_{1}: & \text { CRM implementation has some positive effect on customer loyalty. }\end{cases}$ \\
& $\begin{cases}H_{0}: & \text { CRM implementation has no effect on customer awareness. } \\
H_{1}: & \text { CRM implementation has some positive effect on customer awareness. }\end{cases}$
\end{tabular}


The second hypothesis examines whether implementation of CRM influences on market performance in terms of reduction on customer complaints, quality improvement, improving customer perception, access to services and increase in market share. Table 2 demonstrates the summary of the subhypotheses,

\section{Table 2}

The summary of the second sub-hypotheses

\begin{tabular}{ll}
\hline Hypothesis & Description \\
1 & $\begin{cases}H_{0}: & \text { CRM implementation has no effect on reducing customer complaints. } \\
H_{1}: & \text { CRM implementation has some positive effect on reducing customer complaints. }\end{cases}$ \\
2 & $\begin{cases}H_{0}: & \text { CRM implementation has no effect on quality of services. } \\
H_{1}: & \text { CRM implementation has some positive effect on on quality of services. }\end{cases}$ \\
3 & $\begin{cases}H_{0}: & \text { CRM implementation has no effect on customer perception. } \\
H_{1}: & \text { CRM implementation has some positive effect on customer perception. }\end{cases}$ \\
4 & $\begin{cases}H_{0}: & \text { CRM implementation has no effect on customer's access to services. } \\
H_{1}: & \text { CRM implementation has some positive effect on customer's access to services. }\end{cases}$ \\
5 & $\begin{cases}H_{0}: & \text { CRM implementation has no effect on market share. } \\
H_{1}: & \text { CRM implementation has some positive effect on market share. }\end{cases}$
\end{tabular}

Finally, the third hypothesis considers the effect of CRM on financial figures in terms of sales growth, profit growth, earnings per share and productivity. Table 3 demonstrates the summary of various sub-hypotheses,

\section{Table 3}

The summary of the third sub-hypotheses

\begin{tabular}{ll}
\hline Hypothesis & Description \\
1 & $\begin{cases}H_{0}: & \text { CRM implementation has no effect on sales growth. } \\
H_{1}: & \text { CRM implementation has some positive effect on sales growth. }\end{cases}$ \\
3 & $\begin{cases}H_{0}: & \text { CRM implementation has no effect on net profit growth. } \\
H_{1}: & \text { CRM implementation has some positive effect on net profit growth. }\end{cases}$ \\
4 & $\begin{cases}H_{0}: & \text { CRM implementation has no effect on dividend yield. } \\
H_{1}: & \text { CRM implementation has some positive effect on dividend yield. }\end{cases}$ \\
& $\begin{cases}H_{0}: & \text { CRM implementation has no effect on productivity of marketing expenses. } \\
H_{1}: & \text { CRM implementation has some positive effect on productivity of marketing expenses. }\end{cases}$
\end{tabular}

As we can observe, there are 13 questions associated with the proposed study of this paper and all questions have been arranged in Likert scale from 1 to 5 . There were 90 managers in province of Tehran, Iran who worked for the telecommunication business and we distributed all questions among them. Cronbach alpha has been calculated as 0.911, which validates the overall questionnaire. Kolmogorov - Smirnov has been used for normality of the data, which was gathered and the results confirmed that all data were normally distributed. Therefore, we can use t-student test to verify hypotheses. For all hypotheses the null hypothesis is $\mu \leq 3$ and the alternative hypothesis is $\mu>3$. 


\section{The results}

In this section, we present details of testing three main hypotheses as well as all sub-hypotheses. Table 4 summarizes the summary of testing various hypotheses.

Table 4

The summary of testing various hypotheses

\begin{tabular}{clccccccc}
\hline \multicolumn{3}{c}{ Customer perception } & \multicolumn{3}{c}{ Market performance } & \multicolumn{2}{c}{ Financial figures } \\
\hline Q. & \multicolumn{1}{c}{ Variable } & Result & Q. & Variable & Result & Q. & Variable & Result \\
\hline 4 & Customer satisfaction & Reject & 2 & Customer complaints & Accept & 1 & Sales growth & Accept \\
3 & Customer perception & Reject & 6 & Customer retention & Reject & 7 & Increase in profit & Accept \\
10 & Customer loyalty & Reject & 5 & Quality of services & Accept & 8 & Increase in DPS & Accept \\
11 & \multirow{2}{*}{ Customer awareness } & Reject & 9 & Access to services & Accept & 13 & \multirow{2}{*}{ Marketing expenses } & Reject \\
\hline
\end{tabular}

As we can observe from the results of Table 4, questions 3, 4, 10 and 11 are associated with customer perception and the first null hypothesis is rejected in all four cases. Therefore, we can conclude CRM influences customer's perception in terms of customer retention, satisfaction, loyalty and awareness. In addition, questions 2, 5, 6, 9 and 12 are associated with market performance and in most cases, the null hypothesis was accepted and only in the case of customer retention, the null hypothesis is rejected. Overall, we cannot confirm the second hypothesis. Finally, questions 1, 7, 8 and 13 were associated with financial figures and as we can see from the results of Table 4, CRM was effective in case of reducing marketing expenses and had no impact on sales growth, profit improvement or dividend per share (DPS) increase.

\section{Conclusion}

In this paper, we have presented an empirical investigation to find the effect of CRM on customer perception, market performance as well as financial figures in one of telecommunication firms in city of Tehran, Iran. The results of our survey confirmed that having a CRM could contribute on customer perception but does not significantly influence on market performance or financial results. The surveyed people believed CRM could reduce marketing expenses and preserve more customer retention but it does not have any meaningful influence on quality of services, reducing customer complaints or improvement on accessing services. According to our survey results, CRM cannot increase sales figures or profit either.

\section{References}

Chang, W., Park, J. E., \& Chaiy, S. (2010). How does CRM technology transform into organizational performance? A mediating role of marketing capability. Journal of Business Research, 63(8), 849855.

Keramati, A., Mehrabi, H., \& Mojir, N. (2010). A process-oriented perspective on customer relationship management and organizational performance: An empirical investigation. Industrial Marketing Management, 39(7), 1170-1185.

Peltier, J. W., Zahay, D., \& Lehmann, D. R. (2012). Organizational learning and CRM success: a model for linking organizational practices, customer data quality, and performance. Journal of Interactive Marketing.

Wu, S. I., \& Li, P. C. (2011). The relationships between CRM, RQ, and CLV based on different hotel preferences. International Journal of Hospitality Management, 30(2), 262-271.

$\mathrm{Wu}, \mathrm{S} . \mathrm{I} .$, \& Chen, J. H. (2012). Comparison between hotels and motels using CRM effect model-An empirical study in Taiwan. International Journal of Hospitality Management, 31(4), 1254-1263. 